\title{
Location-Based Services and Privacy in Airports
}

\author{
John Paulin Hansen ${ }^{1}$, Alexandre Alapetite ${ }^{2}$, Henning Boje Andersen ${ }^{2}$, \\ Lone Malmborg ${ }^{1}$, and Jacob Thommesen ${ }^{2}$ \\ ${ }^{1}$ IT University of Copenhagen \\ Rued Langgaards Vej 7 \\ DK-2300 Copenhagen S, Denmark \\ \{paulin, malmborg\} @itu.dk \\ ${ }^{2}$ Technical University of Denmark \\ Department of Management Engineering \\ Produktionstorvet 426 \\ DK-2800 Kongens, Lyngby, Denmark \\ $\{a l a l, b o j e, j a c t\} @ m a n . d t u . d k$
}

\begin{abstract}
This paper reports on a study of privacy concerns related to locationbased services in an airport, where users who volunteer for the service will be tracked for a limited period and within a limited area. Reactions elicited from travellers at a field trial showed $60 \%$ feeling to some or to a large degree more secure with the system in operation. To provide a background for the privacy study we also describe services provided by the tracking facility and the infrastructure behind it as well as the design and evaluation activities we used. Based on project results including a large number of comments from passengers, we discuss factors influencing passengers' acceptance and appreciation of location-based services in airports.
\end{abstract}

Keywords: Location-based services, Mobile services, Tracking, Technology acceptance, Privacy, Transport.

\section{Introduction}

More and more mobile phone models appear with facilities that allow people to locate themselves, which in turn allow service providers to track the position of the phones. Similarly, future travel documents and photos may contain electronic tags that will make them traceable throughout the journey.

Privacy concerns for ubiquitous computing and location-based services have been examined in different contexts in earlier research (e.g. [1]). Design experiences reported in this paper come from the SPOPOS project [2], which has developed a technical infrastructure to track people and objects indoors and to provide location-based services to passengers and airport operators. Tracking data and user reactions have been collected during 2007-8 to direct the final design of services offered. The airport is using the location technology to improve its ability to predict the build-up of queues and - in the long run - to ensure that passengers get to their plane on time. 
When departing from an airport, passengers want to have information about: 1) boarding time and gate number, including all relevant changes; 2) location of their gate and how to find it - in larger airports, way-finding may be a serious problem; and 3) the time it will take to go to their gate - depending on actual distance, internal airport transport service and queues on the way. To what extent can location-based services provide this information? Are passengers willing to give up some amount of privacy and be tracked in order to obtain the information when they are just passing through a transitional public place?

\section{The Airport Case}

An airport can be a challenging environment for both passengers and operators. Passengers may have positive as well as negative expectations, they may have some anxiety about delays, sudden change of gates and some may suffer from fear of flying. Frequent travellers need efficiency, and occasional passengers need security, the right information, and in general, peace of mind. But it is not easy to satisfy these needs. An airport is a very complex logistic system, and operators must deal with queues and transfer of baggage, they must guide passengers through a number of control points, provide services for different kinds of passengers during their stay, comply with strict security procedures and - most basically - they are running a business to generate a revenue for the airport owners.

\subsection{Infrastructure}

The SPOPOS system is an indoor, location-based platform developed to deliver transient services. The platform may be used at several public locations, for instance, railways, shopping malls, stadiums or museums. The service design was guided by our airport case while the technical infrastructure can be applied broadly.

Most people bring their mobile phones along when travelling - 93\% according to a recent survey [3]. In a few years, electronic boarding passes may emigrate from kiosks and Web check-in into mobile phones (various approaches are being investigated by IATA - the International Air Transport Association [4]). The increased use of mobile phones for handling travel information prompted the project team to develop an integrated location-based service system for passengers, airlines and airport operators. The system deploys Bluetooth and RFID location detection to track passengers. Each detection method is able to show in which "zones" a passenger is located within a rough circle with a radius of roughly 30 meters (see Figure 1). The actual sizes of the zones vary widely because of signal reflections etc. However, due to privacy concerns we do not in fact seek to obtain any higher accuracy, although it would be possible to achieve this using, e.g., triangulation techniques.

Since 2001, Copenhagen airport has offered free SMS departure alerts to its Danish and Swedish customers. This service was used more than 1 million times in 2007. SPOPOS improves on existing communication and information by offering locationspecific messages and additional information. The timing of SMS messages can now be relative to passenger location, and if the passenger is moving through zones towards the gate we can avoid sending a notification. If the passenger is not moving 
towards the gate (or moving in the wrong direction) the SMS system may be set to respond with increasing levels of urgency.

Since Internet access from mobile phones is now becoming more and more common (e.g., via 3G, Wi-Fi), the SPOPOS project proposes a simple Web interface combined with Bluetooth or RFID localisation. The main advantages of this solution is that it does not require the user to install any additional program, it works on all types of Web-enabled devices, and users are more skilled at and comfortable with using their Web browser than installing new programs on their mobile phone. The small drawback is the very modest cost of data traffic - in case the location does not offer free Wi-Fi.

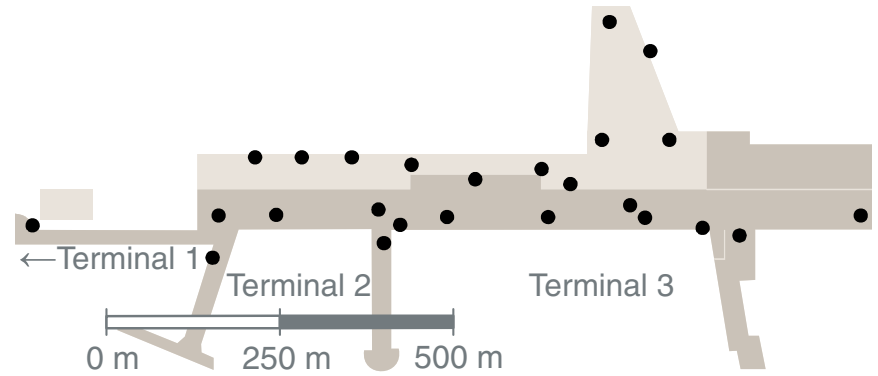

Fig. 1. Placement of Bluetooth and RFID antennas at Copenhagen Airport. Each zone is covered by both systems.

With each of the technologies, Bluetooth and RFID, a prior registration is needed to match a given passenger's mobile phone number with a tracking ID. The MAC address of the phone may be entered either from the passenger's home via the airport website or - in the near future - from a kiosk in the airport. Passengers with no registration may still provide some information to the airport operators, because if they have a Bluetooth equipped mobile phone that is turned on and which is not made invisible, they can then be tracked in an anonymous mode. This can accurately measure the time that passengers spend in particular areas and queues. However, since it is only a fraction of the passengers who keep their Bluetooth visible, this passive tracking is useful only for identifying common patterns in the flow of passengers.

In our field trials (see section 4) we used active RFID tags with batteries that emit a signal every 3 seconds when moved and every 20 minutes when not moved (they contain an accelerometer). RFID tags are an interesting technology for indoor tracking since they have a long battery-life ( $\sim$ years), a reasonable cost, and thus may be permanently mounted on e.g. baggage trolleys.

Initial measurements indicated an almost $100 \%$ success rate in detecting target passengers when they passed security, pier and gate, with both Bluetooth and RFID. Statistics for RFID and Bluetooth tracking looked similar, in particular with regard to the time difference between two detections of the same passenger. Most passengers inside a tracking zone are detected with intervals of less than 5 seconds and less than $5 \%$ remain unseen for more than a minute. 


\subsection{Location-Based Services for Operators}

Increased security levels in airports increase the time passengers spend waiting for inspection and passport control. A queue can build up suddenly, and some passengers may become critically late while waiting in line. The SPOPOS tracking facilities make it possible for airport management to see passenger flow and congestions in real-time, and therefore, e.g., if and when a queue is accumulating at a particular control point. In turn, this overview provides airport staff with an option to increase the manning on the control point immediately (Figure 2).

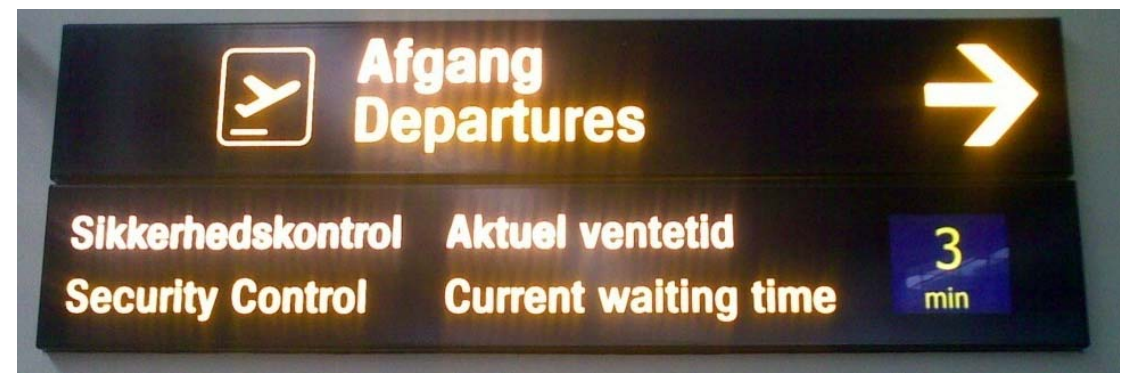

Fig. 2. Tracking of Bluetooth mobile phones provides real-time information to passengers and security managers on waiting time. The information is also published at the airport's webpage.

Getting passengers on-board a flight is achieved by pushing information about departure time, gate number and boarding status to information displays. The pushapproach has been optimized for decades but still it has some serious drawbacks. Passengers do not always pay attention to the information displayed; sometimes they misread the displays and sometimes they simply forget the information. Most modern airports are reluctant to use public loudspeakers and they do so only when passengers are about to miss their flight. Copenhagen Airport, with 21 million passengers departing per year (2008), is forced to make numerous public calls for late-at-gate passengers on a busy day, even though the airport strives hard to be a "silent airport".

The SPOPOS project was initiated by the commercial department of Copenhagen Airport for several reasons: Most importantly, it will generate large amounts of data needed for passenger flow analysis: How many people pass through a particular shop area? How long time do passengers dwell in specific rest areas? SPOPOS can accurately document, e.g., changes in passenger movements when new procedures for timing of announcements are introduced.

The airlines want passengers to arrive at their gate, if not as early as possible, then early enough to ensure that nobody is late. On the other hand the airport wants to keep passengers in the shopping area as long as possible and most passengers wish to spend as little time as possible waiting at the gate.

The observation that location-based systems may help passengers reach their gate in due time is not novel (e.g., [5]). However, as several researchers also have pointed out (e.g. [6]), location-based systems raise several privacy concerns, and if most passengers reject the system, it has little effect: i.e., the risk of delayed departures is only reduced substantially if a large proportion of passengers agree to use the system. So 
the big question is: can a system be designed which a large majority of passengers will accept?

\subsection{Location-Based Services for Travellers}

Airports invest considerable resources into putting out information about flight status. Unless passengers feel entirely updated about their flight, they are not relaxed and they may be uncertain about how much time they may spend on shopping, eating and leisure activities.

The design purpose of SPOPOS Gatecaller service is to reduce uncertainty that passengers experience and make them less liable to miss their flight. Airport operators will have fewer departures delayed due to missing passengers and, in the long run, more relaxed and satisfied passengers.
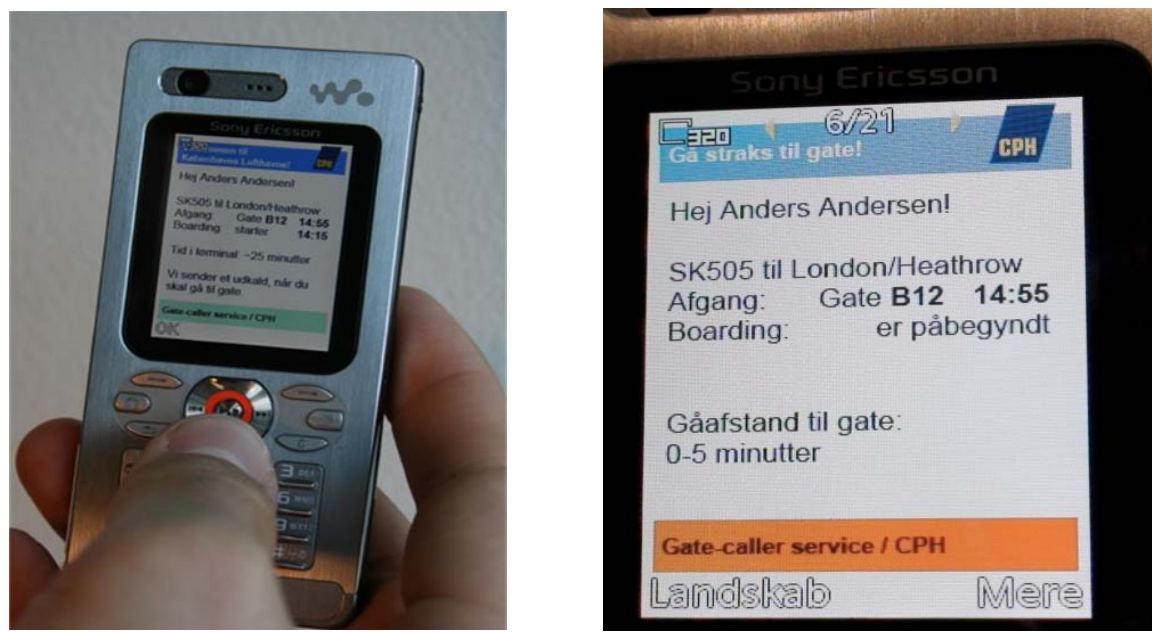

Fig. 3. The basic Gatecaller system informing passengers on when to go to gate, dependent on their current location. The picture to the right shows the message sent automatically when boarding has started to a passenger who has not yet shown up at the gate.

The basic Gatecaller is an automatic, observer-free, continuous and synchronous location system. No human observer (airport personnel) is involved. The service sends information about boarding and departure changes directly to the cell phone of the individual passenger, who will now no longer depend on access to information screens. Information and timing are based on the passenger's location and include estimated walking time to the gate (see Figure 3 ).

The extended Gatecaller allows gate personnel (i.e., a 'stranger') to locate and contact a passenger who is about to miss his or her departure. The gate personnel can monitor all passengers for a particular flight departure to check if anyone may be so far away that an alert is needed (see Figure 4).

The "Tag-along" expansion of the Gatecaller allows friends and relatives to observe the traveller's movements between zones from a password-protected Web page. 


\section{Spopos PAX Trace}

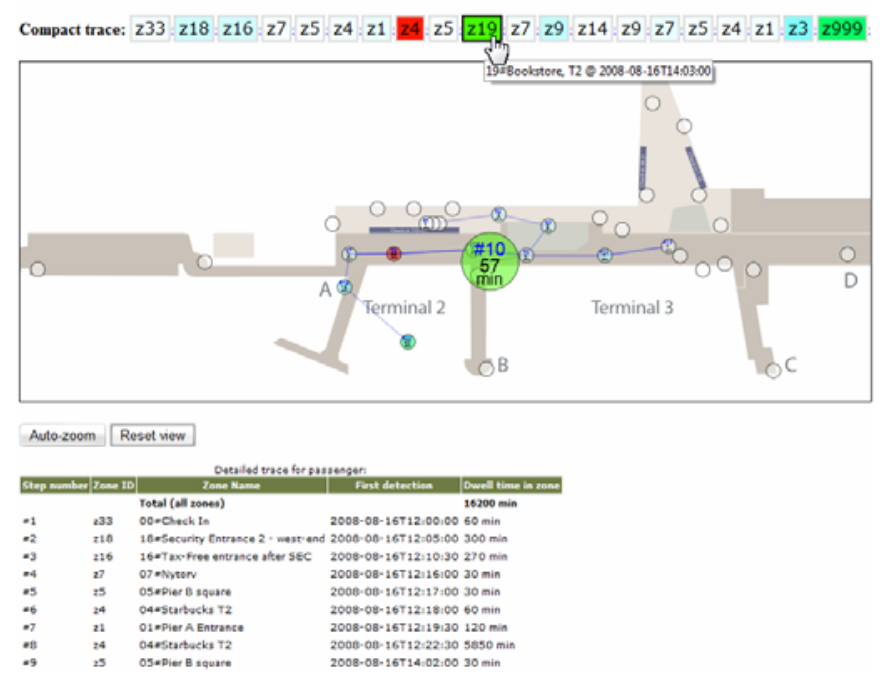

Fig. 4. Operators' view of a single passenger's route throughout the airport

For instance, one would be able to monitor, say, one's elderly parents or teenage children when they are airside. The interface is a simplified version of the map-view (Figure 4) provided to the airport professionals.

When a passenger who has used the SPOPOS services leaves the airport, all location data that refer to a specific mobile phone or ticket are deleted and only anonymous data are stored and used for statistical purposes - similar to current data capture by the airport of number of passenger by flight, airline, day and time etc.

\subsection{Privacy Implications of the Gatecaller}

Normally, privacy is used as a means for maintaining both security and maintaining social roles by managing the image that we present of ourselves to others (e.g. [7]). Thus, while we to a large extent share privacy with friends and relatives, we also require individual privacy by keeping secrets even within intimate relationships. A variety of 'domains' can be regarded as private and thus subject to potential invasions (or loss of privacy): a physical sphere such as a private home; sensitive personal information; personal relations and conversations; activities and decisions. Our privacy can be invaded by physical intrusion, by someone acquiring sensitive information about us, and/or by being observed and judged by others [8].

Even though the airport is not a private place, passenger may still expect some degree of privacy, not least because they are normally protected by anonymity, a basic means for privacy protection. They want to have private conversations without others' eavesdropping on them, or to meet people or make purchases without being profiled for some purpose.

Basically, the privacy implications of a service like the Gatecaller depend not only on the information provided, but also on the identity of the observer (e.g. [1]). Thus, 
on the one hand, location-based information may suggest behaviour (movements), purchasing and personal relationships (co-location with other passengers) - depending on the degree of accuracy. But the three services offered by the Gatecaller differ significantly in terms of the observer: the extended service seems to imply a greater loss of privacy, because the passenger is now being observed and to some extent judged by someone who will meet the passenger at the gate. The 'Tag-along' service may offer the comfort of being watched by close friends or relatives, but it also threatens the individual privacy that the passenger may wish to keep - by making it difficult to indulge secret habits.

\section{Design Methods}

We regard technology as a mediator in human activity. This implies acquiring a detailed understanding of the human activities that technological services will augment, i.e., passenger activities and operator activities. Passengers bring mobile phones, they care about surveillance and privacy, they pay only short visits to the airport, and some passenger activities in the airport are entirely "free" or up to the passengers themselves to decide on (shopping, sitting in a cafeteria, etc.). Operators work on standard personal computers and terminals on fixed locations in the airport, and they use a range of applications as part of their professional job function, required for specific tasks related to handling passengers in the airport.

Initially we developed a couple of short scenarios and personas to establish a shared understanding and starting point among the industrial and academic partners in the project. The topics of six extended scenarios were chosen in agreement with the site operator to span a range of important actors. Personas representing different passenger groups were then developed. They included a typical business traveller who aims at efficiency during his stay, seeking to minimize his waiting time and get the most possible work done while in the airport. At the other end of the user spectrum we developed an absent-minded teenager travelling on her own for the first time. For this persona the predominant design issue centred around feeling secure - and not least, letting her parents feel secure; and this sparked the idea of developing a "Tagalong" function in the Gatecaller that will allow people outside the airport to see the approximate location of friends or family inside the airport, provided they get the passengers' permission to do so. We also expanded on an idea of a locationdependent treasure hunt for this teenager. Time constraints soon forced us to abandon this idea, since the scenario made it clear how much additional system development it would take to implement it.

The personas and scenarios served to communicate and ultimately confirm the goals of SPOPOS. While presenting and discussing the scenarios with airport professionals in the project group, we were able to align researchers', technologists' and professional users' understanding of activities in the airport. Later, we used the scenarios to specify usability requirements, raise design issues and reveal open questions regarding the system architecture.

Observations in the airport helped us to detail and adjust our understanding of passenger and operator activities. We spent a long time in the airport observing passengers and staff. The area around the main information boards and the information 
desks in the transfer area turned out to be the most interesting places to observe passengers, since passengers would often come by and ask for directions, flight departures and other information, which we then later discussed as candidates for possible inclusion in the SPOPOS service.

Moreover, during our observations we often noticed passengers standing still for a very long time in front of the large information boards, simply waiting for the gate of their flight to be announced. As soon as the information appeared, they would begin to move, heading directly for their gate. This demonstrated to us that a not-so-small minority of passengers are seriously hampered by their concern not to miss their flight. For the airport as well as for the passengers this is not a favourable situation. The airport prefers the passengers to spend their waiting time in the shops or the restaurants or at least in the waiting areas and not thronged together in front of the boards and obstructing other traffic. Equally, for the passengers it is of course very tiring to be standing for a long time waiting for the gate announcement. They would have had a more pleasant stay in the airport if they had been given flight information on a mobile device, filtering out irrelevant information about other flights.

Understanding of operators' work processes at the airport was gained by interviewing staff in Copenhagen Airport, including in particular the marketing department, and by following service staff around and observing their professional activities for extended periods.

For several years the marketing department has collected large amounts of data about passenger flow, passenger segments (nationality, age, gender, business/pleasure, airline etc.), shopping behaviours, and dwell times. These data formed a useful ground for our work with personas. A number of the analytical methods developed by the marketing department could be implemented directly in the management module of SPOPOS.

When the Bluetooth / RFID antenna infrastructure became operational we developed passenger prototypes for the Gatecaller service (Figure 3). The prototypes served to give a better understanding of mobile interaction challenges in an airport. Some of these challenges include noise and strong sun light, the fact that passengers typically carry baggage and shopping bags, that they are concerned with following airport procedures (security, gate information, etc.), and that some of them are more or less occupied with taking care of other passengers (young children or elderly).

We made a first prototype of the Gatecaller service and tested it in the airport on three mobile phones in June 2007. It was based on real flight and passenger data, but pushing Bluetooth notifications with gate and departure information to passengers' mobile phones was simulated. Evaluation of the prototype was done by a Wizard-of$\mathrm{Oz}$ session, a method that was a useful and needed substitute for an evaluation of a working prototype, since the connection between the Bluetooth server and the passenger and flight databases had not yet been established. Passenger notifications were pushed manually to the three mobile phones when required. The session was run as a real passenger situation, but with project members acting as passengers: The passengers checked in for a real departure (in a simulated check-in desk in the transfer area), and received departure information and information about their remaining time at appropriate points of time. 
A second prototype evaluation with the same set-up, but adjusted according to the results from the first evaluation, was done in December 2007. This time, representatives from the press participated in the prototype evaluation, which was highly motivating and helped us making more precise the oral and written introduction given to passengers when asking them to sign up for the system.

The operator prototype has been tested by heuristic evaluations as well as thinkaloud usability tests with airport personnel, providing several suggestions for improvements. Prototypes of the system modules for airline operators were tested at the departure gates in field tests (see next section). Prototypes for overall airport management have also been developed and tested in the final evaluation.

\section{User Evaluation}

Starting in March 2008, a series of test trials were launched with the collaboration of Scandinavian Airlines (SAS) involving passengers who accepted to participate in testing the Gatecaller. At the time of writing two such trials have been run, each involving the recruitment of passengers departing on an SAS charter flight from Copenhagen to Sharm El Sheik in Egypt. On these flights nearly all passengers are travelling in families or groups, and they often include a number of children or elderly family members.

At the check-in line, passengers were contacted by staff, wearing T-shirts with conspicuous SPOPOS logos, and asked if they would like to participate as volunteers in the testing of a new tracking and information service. Passengers who accepted our request were then asked to carry an RFID on their handbag or hand luggage till they reach their gate, and to register their mobile phone (if they have any). Passengers were also told that they would be asked to fill out a short questionnaire on arrival at gate.

Due to congestion at the check-in line, not all passengers could be approached, but nearly all who were so accepted to become volunteer subjects. The total number of successfully recruited subjects in the two field tests was 138, most of whom, 116, had time to complete the questionnaire at gate. The five staff members involved in recruiting passengers reported the ratio of passengers who either refused to participate (mean: $7 \%$ ) or who were too busy with taking care of children or elderly friends (mean: 14\%). No passengers were late at gate in the two trials. In the following we describe some of the questionnaire data including correlations with location data.

There are two significant findings from the passenger surveys. The first is the added comfort a number of passengers feel when they know that the Gatecaller service is running. (This service was not fully implemented for the first departure, so the question was asked to only passengers on the second departure, $\mathrm{N}=76$.) We asked participants: "Has it made you feel more secure that the gate personnel now may find you if you are late?" As can be seen from their answers (table 1), a majority (60\%) feels to some degree or to a large degree more secure with the knowledge that the Gatecaller function is available. 
Table 1. Responses given by passengers at gate to the question "Has it made you feel more secure that the gate personnel now may find you if you are late?"

\begin{tabular}{|l|l|l|l|l|}
\hline$[\mathrm{N}=76]$ & $\begin{array}{l}\text { No, not at } \\
\text { all }\end{array}$ & $\begin{array}{l}\text { No, } \\
\text { hardly at } \\
\text { all }\end{array}$ & $\begin{array}{l}\text { Yes, to } \\
\text { some } \\
\text { degree }\end{array}$ & $\begin{array}{l}\text { Yes, to a } \\
\text { large } \\
\text { degree }\end{array}$ \\
\cline { 2 - 5 } & $20 \%$ & $20 \%$ & $39 \%$ & $21 \%$ \\
\hline
\end{tabular}

The second most significant - and not foreseen - finding is that only a small minority of passengers seem to have felt their privacy affected during the time they have spent carrying the RFID tag that was traced (or had their Bluetooth cell phone traced). We asked respondents: "Have you felt yourself being monitored while you have been carrying the RFID tag?" As can be seen from table 2, few passengers feel themselves subject to monitoring.

Table 2. Responses given by passengers at gate to the question "Have you felt yourself being monitored while you have been carrying the RFID tag?"

\begin{tabular}{|l|l|l|l|l|}
\hline$[\mathrm{N}=116]$ & $\begin{array}{l}\text { No, not } \\
\text { at all }\end{array}$ & $\begin{array}{l}\text { No, } \\
\text { hardly at } \\
\text { all }\end{array}$ & $\begin{array}{l}\text { Yes, to } \\
\text { some } \\
\text { degree }\end{array}$ & $\begin{array}{l}\text { Yes, to a } \\
\text { large } \\
\text { degree }\end{array}$ \\
\cline { 2 - 5 } & $86 \%$ & $9 \%$ & $4 \%$ & $1 \%$ \\
\hline
\end{tabular}

We also asked participants if the time they spent on keeping themselves up to date influenced their movements in the airport.

Table 3. Responses given by passengers at gate to the question "Has time spent on information influenced your movements in the airport?"

\begin{tabular}{|l|l|l|l|l|}
\hline \multirow{2}{*}[\mathrm{N}=98]{} & $\begin{array}{l}\text { No not at } \\
\text { all }\end{array}$ & $\begin{array}{l}\text { No, hardly } \\
\text { any time }\end{array}$ & $\begin{array}{l}\text { Yes, some } \\
\text { time }\end{array}$ & $\begin{array}{l}\text { Yes, a lot } \\
\text { of time }\end{array}$ \\
\cline { 2 - 5 } & $38 \%$ & $27 \%$ & $24 \%$ & $12 \%$ \\
\hline
\end{tabular}

At the same time, there is a significant though modest correlation (Spearman's rho=.26; $\mathrm{p}=.03$ ) between time spent between security and before entering the pier and efforts spent on keeping up to date: i.e., the less passengers have felt their movements influenced by the need for keeping up to date on their departure, the more time they have been able to spend in the tax-free area before going to gate.

\subsection{Evaluation by Airport Personnel}

Staff at the gate is typically quite busy from the time they open the gate till the last passenger has embarked. One of the most critical tasks for the gate personnel today is to decide on the effort and time to spend on finding passengers who have checked in but who have not shown up at gate. The second greatest advantage of the SPOPOS Gatecaller is that it allows gate personnel an easy overview of where late passengers 
are and an opportunity to alert them or call them by phone. During the two trials that have been made so far, four persons from the SAS ground staff evaluated the system.

Staff reactions were uniformly and emphatically positive. At the present time, they have an entirely adequate overview of the number (and names etc.) of passengers who have checked and who have still not shown up at the boarding check-in. But they have no means of knowing where they are. The Gatecaller concept promises to change this. One of the senior gate staff participants stated that he "hoped that this technology will be implemented during my career". Another remarked that the boarding process could possibly be "turned $180^{\circ}$ now". In our interpretation, she foresees a transition from the present push-approach towards a future 'pull-to-gate' procedure.

\section{Discussion}

There is now evidence that a large proportion of travellers in Copenhagen airport will accept and use the kind of location-based services that the Gatecaller will provide, if they are offered this. It is, however, an open question if this finding will generalize to other transitional spaces also. First and foremost, airports are special locations with regard to privacy. For many years, surveillance has been so prevalent in airports that we quietly accept it, as Adey [9] points out. Passengers are frequently asked to have their baggage examined, to take off their belt and shoes and they are used to technologies like CCTV cameras being part of an airport location. We got several comments from passengers interviewed at the gate, indicating that they are particular in their acceptance of being tracked by service providers in airports, but not in general:

"I don't mind using the tracking service (.....) in this airport. Here I can see the benefits. I would not use it in the shopping mall, where they would hunt me down with "offerings" all over the place" (Danish female, 40 years)

It is also important to people, that they have trust in the organization or people who requires information about their locations, cf. [1]. Copenhagen Airport is partly owned by a government that people trust in most other matters. One passenger addressed this:

"I have no worries that information handled within governmental institutions would ever be used in any harmful way" (Dutch male, 34 years).

Another passenger pointed out to us that trust is built on honesty that should be confirmed:

"Honesty is important for tracking. I would only allow companies that I trust to trace me and they should show themselves worthy of the trust..." (Danish male, 34 years)

A recent survey [3] asked passengers if they would "accept that an airline/ airport use their location sensing technology in order to locate you and better guide you through the airport terminal?" The percentages of people who answered "yes" to this 
differed dramatically from airport to airport. In one case (Charles de Gaulle, France) only $4 \%$ would accept to be tracked, while the other 5 airports had acceptance rates between $40 \%$ and $69 \%$. We do not have any data that can serve to explain the difference between the results of that survey with those we have obtained. However, it may be speculated that an approach to passengers that stresses openness and the fact that it is voluntary and that personal data will be deleted as soon as the passenger leaves the airport may play a role. The fact that people in our field test had actually experienced being tracked may have convinced them that this is rather harmless. In a recent study Tsai et al. [10] found that privacy concerns were reduced after people have had the experience of using a mobile location sharing system.

In the SPOPOS project we decided to invite the public news media to one of our field test. We also decided to implement the "Tag-along" service, partly because we wanted to make it commonly known how passenger's individual locations may be traced indoors, and partly because some passengers expressed great expectations to it.

The sensitivity of the private information increases with the accuracy of tracking, i.e., people are less concerned if their whereabouts are only roughly known. In the current version, the SPOPOS system is able to locate passengers only in wide zones, and the zones are so large that nobody will be able to tell which particular shop or cafeteria a passenger might be visiting. On passenger commented on the issue of granularity:

"I like the idea of this system. But I would not like it to know in detail when I am at the restroom" (Polish female, 24 years)

Brown et al. [11] deliberately designed the 'Whereabouts Clock' - a device to show the location of other family members - so that it would reveal their whereabouts in only coarse-grained terms (i.e. 'home', 'work', 'school' or 'elsewhere').

The SPOPOS Gatecaller is designed to track the passengers themselves. Nevertheless, there still is some room for anonymity, without inhibiting the underlying purpose of locating 'delayed' passengers. For most of the passengers, it would be sufficient only to be identified as an anonymous member of a group: the passenger list for a particular flight. It would be necessary to identify only the few passengers who do seem not to arrive in due time for boarding. Some passengers are aware of this:

"The system is a kind of surveillance. But there is a huge difference between [constantly] following a person on a screen or only gaining information when the gate is about to close." (Danish male, 34).

If location-based services are introduced at other public places, we expect that it would be acceptable to most potential users only if is able to justify itself by offering some services that are perceived useful. What those services might be are specific to the different places. Costumers in a shopping centre may appreciate it if they can easily find all the items they have on their shopping list. Spectators at a sports event may appreciate it that they can easily locate their seat. However, just as the "basic version" of the Gatecaller would work without any human monitors involved, we suggest that location-based services for other public spaces should also strive for anonymity if possible and should allow people to opt out, if they feel uncomfortable 
with the trustworthiness of the provider, cf. Kaasinen [6]. In quite a lot of cases where location based systems can be valuable, anonymity can simply be achieved by letting the device be aware of its own location, but without other parties tracking the location cf. Barkhuus \& Day [12].

\section{Conclusion}

A majority of passengers who have tried the Gatecaller service report that they feel more secure knowing that it is working in the background, while only a small fraction of passengers report that they feel themselves monitored. Comments from passengers point to reasons for this high acceptance: people find the service useful; they have trust in the airport operators; they believe that data will be made anonymous after take-off; and they appreciate that it will only be possible for other people to see their approximate location in zones and only when they are about to be late at gate. Finally, airline handlers and airport management express enthusiasm about the information that this service will provide them.

\section{Acknowledgements}

We gratefully acknowledge the involvement from our industrial partners in the SPOPOS project: Lyngsoe Systems A/S, BLIP Systems A/S, Travelmarket A/S and Copenhagen Airports A/S. We also thank Scandinavian Airline Systems for their support in field trials. The research is supported by the Danish Research and Innovation Agency under the Danish Ministry for Knowledge, Technology and Development.

\section{References}

1. Lederer, S., Mankoff, J., Dey, A.K.: Who wants to know what when? privacy preference determinants in ubiquitous computing. In: CHI 2003 Extended Abstracts on Human Factors in Computing Systems. CHI 2003, pp. 724-725. ACM, New York (2003)

2. SPOPOS, http: / /www. spopos. dk (confirmed April 12, 2009)

3. SITA/air transport world passenger self-service survey, http://www.sita.aero/files/resources/SITA_PSS_2008.pdf (confirmed April 12, 2009)

4. IATA - International Air Transport Association, Simplifying the Business, http: / / iata.org/stb/ (confirmed April 12, 2009)

5. Raper, J., Gartner, G., Karimi, H., Rizo, C.: A critical evaluation of location based services and their potential. Journal of Location Based Services 1(1), 5-45 (2007)

6. Kaasinen, E.: User needs for location-aware mobile services. Personal Ubiquitous Computing 7(1), 70-79 (2003)

7. Fried, C.: Privacy. Yale Law Journal 77(3), 475-493 (1968)

8. Introna, L.D.: Privacy and the Computer: Why We Need Privacy in the Information Society. Metaphilosophy 28(3), 259-275 (1997)

9. Adey, P.: Secured and Sorted Mobilities: Examples from the Airport. Surveillance \& Society $1(4), 500-519$ (2004) 
10. Tsai, J.Y., Kelley, P., Drielsma, P., Cranor, L.F., Hong, J., Sadeh, N.: Who's viewed you?: the impact of feedback in a mobile location-sharing application. In: Proceedings of the 27th international Conference on Human Factors in Computing Systems. CHI 2009, pp. 2003-2012. ACM, New York (2009)

11. Brown, B., Taylor, A., Izadi, S., Sellen, A., Kaye, J.: Locating Family Values: A Field Trail of the Whereabouts Clock. In: Proc. of Ubi Comp 2007, pp. 354-371. Springer, Godalming (2007)

12. Barkhuus, L., Dey, A.K.: Location-based services for mobile telephony: a study of users' privacy concerns. In: Proceedings of INTERACT 2003, 9th IFIP TC13 International Conference on Human-Computer Interaction, pp. 709-712 (2003) 